\title{
MODELO EDITORIAL Y MORFOSINTAXIS MATERIAL DE UNA EDICIÓN DE MARTÍN NUCIO: LA QÜESTIÓN DE AMOR Y LA CÁRCEL DE AMOR (1546)*
}

\author{
Josep Lluís Martos \\ Universitat d'Alacant \\ jl.martos@ua.es
}

En la primera versión de su estudio introductorio al facsímil de la editio princeps del Cancionero de romances, Ramón Menéndez Pidal refería una edición parisina de la Qüestión de amor con tres romances finales, que no es otra sino la que salió de las prensas de Hernaldo Caldera y su hijo, Claudio Caldera, en $1548^{1}$, que incluía también la Cárcel de amor de Diego de San Pedro $^{2}$. Pocos años después de la publicación de este facsímil y partiendo de la referencia pidaliana a este impreso, Hilka dio noticia de una edición algo anterior, de 1546, con estos mismos contenidos:

*Este trabajo se enmarca dentro del proyecto Cancionero, romancero y fuentes impresas, del Ministerio de Economía, Industria y Competitividad (FFI2017-86313-P), financiado por la Agencia Estatal de Investigación (AEI) y el Fondo Europeo de Desarrollo Regional (FEDER/UE), del cual soy investigador principal.

${ }^{1}$ Para estos impresores, véase, respectivamente, las entradas 1134 y 1131 de Jean-Dominique Mellot y Elisabeth Queval, Répertoire d'imprimeurs/libraires (vers 1500-vers 1810), París, Bibliothèque Nationale de France, 2004.

${ }^{2}$ «Fol. 175v-179. Un dia de Sant Antón; Obispo don Gonzalo. Quexo me de vos, el rey; Duque de Guimaraes. En essa ciudad de Burgos; Los cinco maravedís. De una ed. anterior del pl. s.: "Síguense quatro rom. El primero es de los cinco maravedís; el segundo es Un dia de Sant Anton; el tercero es Ya cavalga Diego Laynez (v. nota al fol. 155v.) y el quarto Quéxome de vos, el rey. Ahora nuevamente impressos. año de 1559" (Durán I, p. LXXIxb: Gallardo I, col. 1118; otra edic. de 1564, Smmlung Prag., n. ${ }^{\circ}$ III). El rom. de los cinco maravedís empieza en estas ediciones tardías del pl. s. En Burgos estava el rey; forma del rom. diversa de la del Canc. s. a. Pero la forma de éste debió hallarse en las edic. anteriores de nuestro pl. s., como lo indica el hallarse en una reimpresión parcial de nuestro pliego que se halla al fin de una edición de la Cuestión de Amor, hecha en París 1548: "Aqui comiençan tres romances..." los cuales son: Un dia de sant Anton, Cavalga Diego Lainez y En essa ciudad de Burgos», Ramón Menéndez Pidal, Cancionero de romances impreso en Amberes sin año. Edición facsímil con una introducción, Madrid, Junta para Ampliación de Estudios-Centro de Estudios Históricos, 1914, pp. XxIv-xxv. 
Unter den dankenswerten Nachweisen der Quellen aus pliegos sueltos und früheren Teildrucken findet sich auch [...] der Verweis auf eine Edition der Cuestión de Amor, Paris 1548, die am Schlusse drei Romanzen bringt, diese ohne Zweifel älteren Quellen ensstammend. Uns kam eine Edition bereits von 1546 mit demselben Füllsel zu Gesicht, deren Interesse dadurch erhöht wird, dass sie auch von Martín Nucio gedruckt worden ist. Sie scheint verhälnismässig selten zu sein, da ich sie in den üblichen Handbüchern nicht verzeichnet finde ${ }^{3}$.

No solo era, por tanto, un impreso hasta entonces desconocido por los repertorios bibliográficos, sino que presentaba un interés añadido a su datación: se trataba de una obra salida del taller de Martín Nucio, el mismo que, por aquellas fechas, generaría un proyecto editorial tan novedoso como el Cancionero de romances.

Al revisar su estudio para la segunda edición de este facsímil, Menéndez Pidal incorpora el descubrimiento de Hilka a su anotación de las fuentes, corrigiendo y reelaborando notablemente el pasaje en cuestión, para referir y otorgar protagonismo a esta edición de 1546, en lógico perjuicio de la parisina de 1548 , relegada aquí a una anotación secundaria ${ }^{4}$.

\footnotetext{
${ }^{3}$ Alfons Hilka, «Zwei spanische Miszellen», en Zeitschrift für Romanische Philologie, 43 (1923), pp. 481-483, p. 481.

${ }^{4}$ «Fol. 175v. - 179. Un día de Sant Antón; Obispo don Gonzalo. Quexo me de vos, el rey; Duque de Guimaraes. En essa ciudad de Burgos; Los cinco maravedís. De una ed. anterior del pl. s.: "Aqui comiençan quatro romances, nuevamente compuestos, con un villancico al cabo y unas coplas como se tornó a ganar España" (Smmlung Prag., n. ${ }^{\circ}$ LXIX); los cuatro romances son: Un dia de sant Anton, Ya cavalga Diego Lainez (véase aquí arriba folio 155 v.), Quexome de vos, el rey y En essa ciudad de Burgos; como se ve, en el mismo orden en que los pone el Canc. s. a. De este pliego que en la colección de Praga pertenece a la segunda mitad del siglo XVI, hubo seguramente edición en la primera mitad de esa centuria y la conoció Martín Nucio, pues al publicar la Question de Amor y Cárcel de Amor, Amberes, 1546, le quedaban en el pliego final cinco hojas sobrantes, y "porque no uviese tanto papel blanco", imprimió en tres de los cuatro romances del pliego en cuestión, bajo el rótulo: "AQUI COMIENÇAN TRES ROmances nuevamente compuestos, con un villancico al cabo, como se tornó a ganar España" (véase A. Hilka en la Zeit. für rom. Phil., XLIII, 1923, pp. 481-482); el no ser cinco hojas sobrantes, obligó a suprimir uno de los cuatro romances y las "coplas de cómo se tornó a ganar España", pero se conservó el corto villancico, al cual, por torpeza del abreviador, se atribuyó el asunto de las coplas. La misma Question de Amor se reimprimió en París 1548 con los mismos tres romances al final (Antología de líricos, Ix, 353-369)», Ramón Menéndez Pidal, Cancionero de romances impreso en Amberes sin año, edición facsímil con una introducción [1914], Madrid, Consejo Superior de Investigaciones Científicas, 1945, pp. XXVI-XXVII.
} 
Cuando Hilka describe por primera vez este impreso ${ }^{5}$, no relaciona ${ }^{6}$ la edición de Nucio con la de 1548 de los Caldera $^{7}$, a pesar de que, sin lugar a dudas y de la misma manera que ocurrió con las secuelas peninsulares del Cancionero de romances, era resultado directo del éxito comercial que tuvo la iniciativa nuciana de reunir en una edición conjunta textos sentimentales ${ }^{8}$ con larga tradición editorial ${ }^{9}$.

\section{El modelo editorial}

Esta edición de obras sentimentales impresa en 1546 responde a estrategias editoriales que ya encontramos, incluso, en la imprenta incunable y postincunable: en la edición burgalesa del Repertorio de los tiempos de Andrés de Li y Bernat de Granollachs, impresa en 1493 por Fadrique de Basilea ${ }^{10}$; en Lo procés de les olives y Lo somni de Joan Joan impresos en Valencia por Lope de la Roca en $1497^{11}$; y, probablemente, en dos obras de origen

${ }^{5}$ Hilka, art. cit., pp. 481-482. Hoy se conservan cinco ejemplares, como cataloga Comedic. Catálogo de obras medievales impresas en castellano hasta 1600, coord. y ed. María Jesús Lacarra, Zaragoza, Universidad de Zaragoza. [En línea]. Enlace: <http://comedic.unizar.es/> [Consulta: 12/01/2020]): en la Österreichische Nationalbibliothek (40.Mm.118), en la Biblioteca Nacional de España (R/39980), en la Hispanic Society of America (sin signatura), en la Národní knihovna České republiky (9 L 000156) y en la Stadtbibliothek Ulm (Schad 6905). Hay digitalización de los ejemplares de Viena $<$ http://digital.onb. ac.at/OnbViewer/viewer.faces?doc=ABO_\%2BZ185856101 > y de Praga <https://books.google.cz/books ?vid $=\mathrm{NKP}: 1003279078 \&$ printsec $=$ frontcover $\# \mathrm{v}=$ onepage $\& \mathrm{q} \& \mathrm{f}=$ false $>$.

${ }^{6}$ Podríamos considerar, sin embargo, que está implícito en las palabras de Menéndez Pidal al hablar de la edición de 1548 como una reimpresión de esta misma obra: «La misma Question de Amor se reimprimió en París 1548 con los mismos tres romances al final», Menéndez Pidal, ob. cit., 1945, p. XXVII.

${ }^{7}$ De la cual no parece que Hilka hubiese visto ejemplar alguno.

${ }^{8}$ Marín Pina advierte, sin embargo, que «la idea de unir por primera vez ambos textos parte del editor flamenco, sin embargo, la tendencia de emparejar textos sentimentales no era nueva», Comedic, ob. cit.; y para ello remite a María de las Nieves Muñiz Muñiz, «Sobre la traducción española del Filocolo de Boccaccio (Sevilla 1541) y sobre las Treize elegantes demandes d'amours», en Criticón, 87-89 (2003), pp. 537-551, p. 541. Esto no quita, en cualquier caso, que esta es la primera ocasión en la que ambas obras se imprimen juntas.

${ }^{9}$ «Su repercusión en otras imprentas, manteniendo la tendencia de sus ediciones con mejor acogida, se alcanzó entre dos y cuatro años, y es en esa estela que, más allá de su influencia conceptual en otras colecciones, debemos concebir los Romances de Guillermo de Miles, en Medina del Campo, de 1550, y la Primera parte de la Silva de varios romances, de Esteban de Nájera, en Zaragoza, de ese mismo año, en el que Nucio también editó su segunda edición del Cancionero de romances», Martos, «La fecha...», art. cit., p. 137.

${ }^{10}$ Josep Lluís Martos, «Manuscritos e incunables en el entorno de los Reyes Católicos: el cancionero EM6», en RILCE, en prensa (2021).

${ }^{11}$ Joan Mahiques, «El Espill o Llibre de les dones, La Disputa de viudes i donzelles, el Procés de les olives, el Somni de Joan Joan y la Brama dels llauradors: notas sobre su difusión impresa en el siglo XVI», en La memoria de los libros. Estudios sobre la historia del escrito y de la lectura en Europa y América, 1, ed. de María Isabel de Páiz Hernández, Salamanca, Instituto de Historia del Libro y la Lectura, 2004, pp. 639-654; Josep Lluís Martos, «Sobre l'Spill de la vida religiosa i la impremta», en Zeitschrift für 
franciscano salidas de las prensas barcelonesas de Joan Rosenbach en $1515^{12}$. Las tres ediciones se presentan en dos volúmenes, destinados, en última instancia, a encuadernarse juntos y formar, así, una unidad ${ }^{13}$, a manera de fascículos, como debió de concebirse también el Libro en el qual se contienen 50 romances $^{14}$, para lo que no podemos desatender que dos de estos ejemplos son impresos en Valencia y en Barcelona, en 1497 y en 1515, contextos editoriales nada ajenos a la génesis de esta primera colección de romances.

Tanto Lo procés de les olives, como Lo somni de Joan Joan salen de las prensas valencianas de Lope de la Roca, respectivamente, el 14 y el 25 de octubre de 1497, como indican sus respectivos colofones, pero con un mismo formato y con sendas portadas, si bien en la primera se hace referencia a ambas obras, un rasgo que encontramos también en la edición de Martín Nucio de 1546:
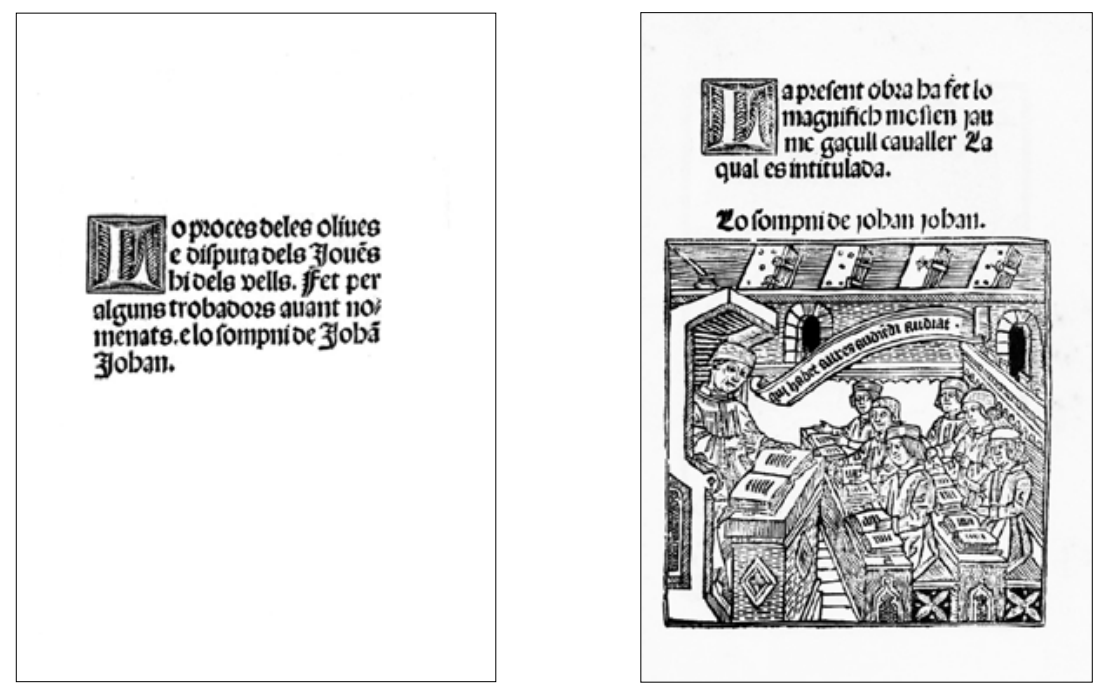

Katalanistik, 25 (2012), pp. 229-258, pp. 240-243; Josep Lluís Martos, «Còpies manuscrites d'impresos renaixentistes a la Biblioteca Universitària de València: el llegat d'Onofre Soler i Rubio», en Caplletra, 56 (2014), pp. 9-41, pp. 33-37.

${ }^{12}$ Martos, «Sobre l'Spill...», art. cit., pp. 240-243.

${ }^{13}$ «Fueron concebidas ya desde esta fecha como partes que ofrecían, para el comprador que lo desease, la posibilidad de adquirir un único volumen, un volumen unitario», Mahiques, art. cit., p. 650.

${ }^{14}$ «Quizá procedente de una edición valenciana, conservamos un ejemplar parcial publicado en Barcelona c. 1525 que, por sus características, parece la primera parte de un proyecto de libro por fascículos», Vicenç Beltran, El romancero: de la oralidad al canon, Kassel, Reichenberger, 2016, pp. 131-132. Para esta colección parcialmente perdida, véase Mario Garvin, «El Libro de cincuenta romances: historia editorial de un impreso perdido», en Zeitschrift für Romanische Philologie, 131:1 (2015), pp. 36-56. 

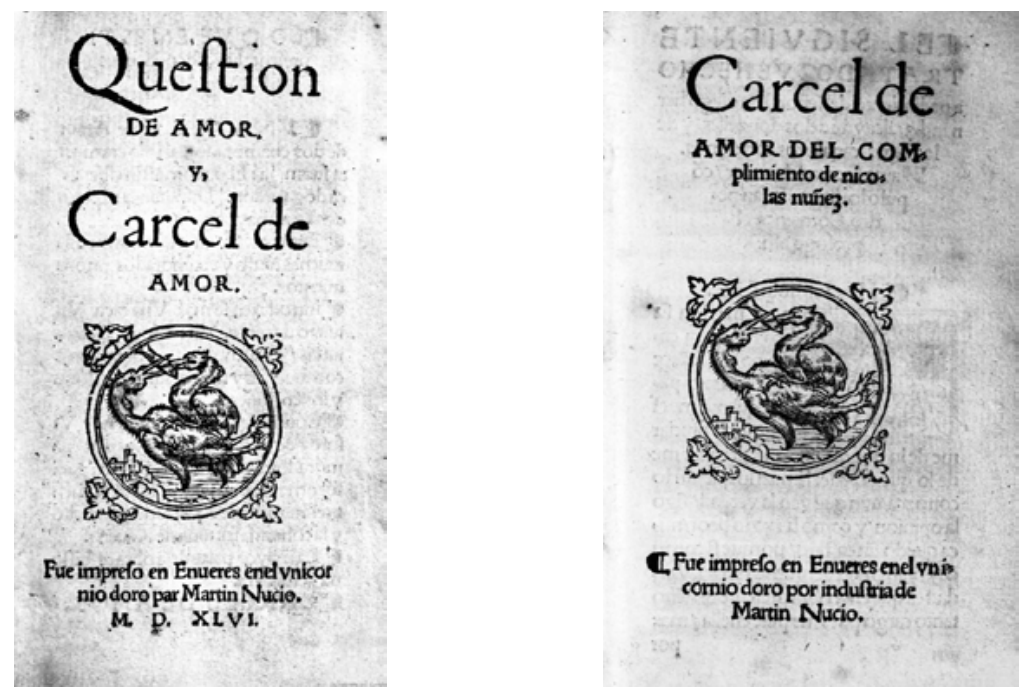

Los impresos de esta edición fasciculada de Martín Nucio se habrían realizado en fechas muy cercanas y de manera consecutiva, como justificarían no solo la lógica editorial, sino también los once días que separan los dos impresos que forman la edición conjunta del incunable valenciano -o los ocho días de los impresos barceloneses- e, incluso, la tabla inicial, que desglosa los contenidos de la Qüestión de amor y se limita a indicar -lo que no es poco, en cualquier caso- el título general de la segunda obra, que, en aquel momento, no debía de estar ni siquiera en cajas:

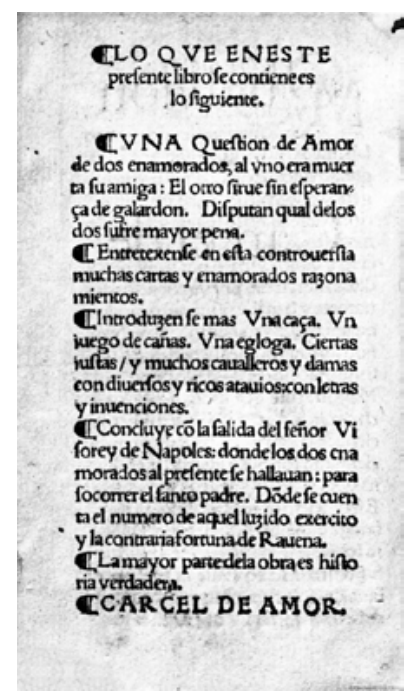


Hoy conocemos 28 ediciones de la Cárcel de amor desde la princeps de 1492 hasta finales del siglo XVI, la última de las cuales, de 1598, es producto todavía de las prensas de los herederos de $\mathrm{Nucio}^{15}$, tras la cual «deja de imprimirse porque no interesa y no resulta ya un producto rentable» ${ }^{16}$. En el contexto de todas ellas, destaca la de 1546 por las razones editoriales que se han ido aduciendo, hasta el punto de que la Qüestión de amor no solo encabezará todas las ediciones posteriores de la Cárcel de amor impresas por Martín Nucio y sus descendientes $(1556,1576$ y 1598), sino también la parisina de 1548 de los Caldera -con la que empezaba este trabajo- y la salmantina de Pedro Lasso Vaca (1580). Si bien la edición zaragozana de Esteban de Nájera $(1551)^{17}$ también reúne ambas obras, invierte su orden y, tras el colofón conjunto para la Cárcel de amor y su Continuación, «con paginación aparte, se edita el Libro llamado Question de amor nuevamente historiado, precedido de dos portadas arquitectónicas idénticas ${ }^{18}$. Se trata, por tanto, de una edición que seguía el modelo editorial de la nuciana, cuya posible venta conjunta o exenta es lo que justificaba, en ambos casos, la utilización de una

${ }^{15}$ Véase, para ellas (algunas nuevas, añadidas a la tradición textual conocida) y para la detección de ediciones fantasma, la entrada de M. ${ }^{a}$ Carmen Marín Pina sobre la Cárcel de amor en el catálogo Comedic, ob. cit., que, con un sólido estudio bibliográfico de las ediciones de esta obra, permite su análisis comparativo, lo que, en buena parte, nos ofrece ella misma en un estudio de conjunto: «La lista que he confeccionado como apéndice de este trabajo, aunque en número es semejante, varía ligeramente con respecto al catálogo de ediciones presentado por Corfis y al elenco de textos acopiado por Alvar-Megías, trabajos ambos de incalculable valor para trazar el recorrido editorial del libro. En relación con su propuesta, considero imaginarias las ediciones de Zaragoza de 1511 y 1532, así como las de Medina del Campo de 1544 y Lovaina de 1580, y sumo a las hasta ahora conocidas cuatro más, algunas de ellas / totalmente ignoradas. Se trata de las ediciones de 1537, 1539, 1542 y ca. 1544», M. ${ }^{\text {a }}$ Carmen Marín Pina, «La trayectoria editorial de la Cárcel de amor en el siglo xvI: avatares en la imprenta», en La literatura medieval hispánica en la imprenta (1475-1600), ed. de María Jesús Lacarra, Valencia, Universitat de València, 2016, pp. 152-172, pp. 152-153. Para la tabla de ediciones, ibidem, p. 172.

${ }^{16}$ Ibidem, p. 171.

${ }^{17} \mathrm{Y}$, por lo que respecta al Cancionero de romances y la Silva de romances, es muy interesante la conexión de este impresor con la producción de la imprenta nuciana de esta época, así como su voluntad de distinción de los productos, que en la edición de 1551 pasa a enriquecerse con grabados y, por ello mismo, a un formato en octavo y a una reordenación de las obras. Para el estudio de estos grabados, ibidem, pp. 162-163; y M. ${ }^{a}$ Carmen Marín Pina, «Adaptación de grabados de Hans Holbein para la Cárcel de amor (Zaragoza, Esteban de Nájera, 1551)», en Janus, 6 (2017), pp. 138-168.

${ }^{18}$ Como advierte Marín Pina, quien, continúa explicando que en su centro «aparece, en la primera, la marca del librero Miguel de Suelves, alias Zapila (un águila con un escorpión en el pico y el lema "VLTIO IVSTA" ['la justa venganza')] y al pie el escudo tipográfico de Esteban de Nájera, y en la segunda, en el centro de la portada arquitectónica, el título del libro. Dichas portadas son idénticas a las empleadas por el mismo impresor en otras publicaciones (por ejemplo, De vini commoditatibus, libellus, 1550)» (Comedic, ob. cit.). «Este grabado lo había utilizado antes Pedro de Castro para decorar la portada de la Question de amor (1545) y posteriormente algún pasaje de la Tragedia Policiana (1547), una obra en la estela celestinesca. Los grabados, en cualquiera de los casos, han perdido por completo toda conexión con el texto de la Cárcel de amor y cumplen la función referencial de informar de la materia a la que pertenecen, la sentimental», ibidem, p. 162. 
misma colección de grabados y, por lo que respecta a la Qüestión de amor, la adición de algún otro nuevo ${ }^{19}$.

Pedro de Castro no recurre a la Qüestión de amor en la inmediata edición de principios de 1547, en Medina del Campo, pero sí que recoge la estrategia de Martín Nucio, asociando aquí la obra de Diego de San Pedro a otra del mismo autor, el Sermón de amores, también de carácter sentimental ${ }^{20}$. Para rematar el último pliego de la Cárcel de amor -en realidad, tras la Continuación o Tratado de Nicolás Núñez-, Pedro de Castro, como Nucio, incorpora poesía, un recurso frecuente ${ }^{21}$, por otro lado, desde los últimos años de la imprenta incunable ${ }^{22}$. Lo hace en las hs. i5v-i8r, tras indicar el «Fin de Cárcel de Amor» (h. i5r); sin embargo, no es un texto ajeno al que le precede, como ocurre con los romances nucianos, sino un poema de Diego de San Pedro, sacado en este caso del Cancionero genera ${ }^{23}$ : aquel que comienza «Dama que mi muerte guía». A continuación se incorpora el Sermón de amores, en un nuevo cuaderno y con una tipografía diferente, tras el cual se vuelve a añadir este mismo poema, aunque con tres estrofas $\operatorname{menos}^{24}$. A diferencia de lo que

${ }^{19}$ «La Question de amor está embellecida con los mismos grabados empleados en la Cárcel de amor más algún otro taco nuevo» (Comedic, ob. cit.).

${ }^{20}$ No hay que buscar un precedente en la pretendida edición de Pedro de Castro de 1544, porque, en realidad, se trata de un impreso sevillano de Domenico de Robertis, que se encuaderna, como facticio, a una edición del Sermón de amores de Cristóbal de Castillejo que sí que sale de las prensas de Medina del Campo en el ejemplar único conservado, como ha demostrado Marín Pina, art. cit., pp. 153-154.

${ }^{21}$ Porque es más fácil de calcular el espacio necesario que en el caso de la prosa y, además, pueden ser textos breves, aunque no es el caso del poema de San Pedro que remata esta edición de Medina del Campo.

${ }^{22}$ Josep Lluís Martos, «La poesia de Joan Roís de Corella: textos de rematada», en Any Roís de Corella, ed. de Ricard Bellveser, Valencia, Institució Alfons el Magnànim, 2013, pp. 487-507.

${ }^{23}$ Lo que marca un precedente de la importancia que Nucio daba a tal colección, a la que recurrió como fuente para su Cancionero de romances y que llegó a reeditar, con añadidos, en 1557. Véase Hernando del Castillo, Cancionero general, 5 vols., ed. de Joaquín González Cuenca, Madrid, Editorial Castalia, 2004; Josep Lluís Martos, «La autocensura en los cancioneros: una justificación impresa en 57CG y otra manuscrita en CT1», en Cultura Neolatina, 70:1-2 (2010), pp. 155-180.

${ }^{24}$ «Tras la Cárcel de amor, y sin transición alguna de páginas o espacios en blanco, se edita el "Tratado que hizo Nicolás Núñez sobre el que Diego de Sant Pedro compuso de Leriano y Laureola, llamado Cárcel de amor" (h. g8v). Al final de esta continuación se lee: "Fin de Cárcel de amor" (h. i5r). Se añaden seguidamente otras obras de Diego de San Pedro anunciadas ya en la portada. Al frente figura la rúbrica "Comiençan las obras de Diego de Sant Pedro y esta primera es una que hizo a una dama de la reina doña Isabel" (hs. i5v-i8r). Las obras anunciadas se reducen, sin embargo, a esta composición, que es el primer poema de Diego de San Pedro que trae el Cancionero General ("Dama que mi muerte guía"), y finalmente el colofón. A todo ello se ha añadido un nuevo cuadernillo con otras obras de Diego de San Pedro, impreso, como ya advirtió Pérez Pastor. Medina, n. 56, con una letrería de cuerpo mayor que la de la Cárcel de amor, "por cuya razón pudieran corresponder a otra edición, ó estar impresos aparte". Se edita en dicho cuadernillo el Sermón ordenado por Diego de Sant Pedro porque le dixeron unas señoras que le desseavan oír predicar. Recuérdese que en el prólogo dedicatoria de la Cárcel de amor, San Pedro dice escribir la obra a petición de don Diego Hernández y ha de ser "del estilo de una oración que enbié a la señora doña Marina Manuel” (Parrilla 1995: 3), es decir, del Sermón. La decisión de editarlos ahora 
pueda parecer, por esta duplicación ${ }^{25}$ y por los rasgos tipográficos de ambas obras, se trata también de una edición conjunta ${ }^{26}$, con llamadas a la unidad editorial desde el prólogo y la portada de la Cárcel de amor, que aquí, como en la edición de Esteban de Nájera, retoma su posición inicial ${ }^{27}$.

Relegar la Cárcel de amor al segundo lugar de la edición de Martín Nucio no cuestiona el valor preponderante de esta obra $^{28}$, sino bien al contrario. No debemos olvidar que es la primera vez que se edita en compañía de otro texto $^{29}$ y que, para ello, se recurre a la estrategia de fascículos. En estas circunstancias, el primero de los impresos anuncia, desde una portada común e, incluso, desde la tabla inicial, la publicación inmediata de otra obra que, ya desde su composición, tuvo gran fortuna literaria y editorial, como estrategia que ceba el mercado para el segundo de los fascículos, publicitándolo, y que invita a sus potenciales destinatarios a que compren también la primera de las entregas, aquella que aporta unidad a un volumen que contendrá la Cárcel de amor. Con ello, además, este segundo impreso está limpio de cualquier remisión a la otra obra, de manera que pueda tener entidad propia para venderse independientemente, con lo que es más que probable que pudiese haber tenido una tirada mayor que la Qüestión de amor.

\footnotetext{
juntos habría satisfecho, por tanto, al noble destinatario. El Sermón comprende 10 hojas y tras él, en el mismo folio, se imprime también la composición antes citada, "Comiençan las obras de Diego de San Pedro y esta primera es una que hizo a una dama de la reina doña Isabel", aunque sin las tres últimas coplas» (Comedic, ob. cit.). Véase también Marín Pina, art. cit., 166-167.

${ }^{25}$ Una duplicación que Marín Pina justifica así, por un proyecto editorial cuyo interés recomendaría, en cualquier caso, volver sobre él: «En esta edición de la Cárcel de amor de 1547 parecen sumarse, pues, varios proyectos editoriales de Pedro de Castro, algunos de ellos inconclusos. Para rellenar el final del cuadernillo, es probable que decidiera ofrecer una pequeña muestra del quehacer poético de Diego de San Pedro, de su poesía amatoria cortesana, acudiendo a la famosa antología poética de 1511, más de media docena de veces reeditada en el siglo xvi. Por otro lado pudo tener en mente editar un volumen exento con el Sermón y su producción poética, que finalmente desestimó y publicó, quizá en una decisión de última hora, al amparo de su obra más famosa, la Cárcel de amor. Lo notificó en la portada, pero no se preocupó de ajustar bien los materiales», ibidem, p. 167.

${ }^{26}$ De hecho, la repetición del poema de remate incide en el carácter fasciculado de la edición, con dos impresos que se reclaman para una compra conjunta, pero que también podían tener una suerte comercial independiente.

${ }^{27}$ Así lo confirma, además, la edición veneciana de 1553, clara secuela de esta, que incorpora las mismas obras y en el mismo orden, aunque reduciendo a una sola aparición el poema de remate, ibidem.

${ }^{28}$ «Las últimas ediciones antiguas de la Cárcel de amor son de la segunda mitad del xvi y en ellas la Cárcel no ocupa un lugar principal, sino que acompaña a la anónima Qüestión de amor», Carmen Parri1la, «Prólogo» a Diego de San Pedro, Cárcel de Amor, con la continuación de Nicolás Núñez, Barcelona, Crítica, 1995, pp. XXXv-LXXXI, p. LXXv.

${ }^{29}$ Más allá de la Continuación de Núñez, que se interpreta como una «constante en la historia editorial del texto» y «como si de una única obra se tratara» (Comedic, ob. cit.).
} 


\section{Materialidad de una edición conjunta ${ }^{30}$}

Esta edición está formada, por tanto, por dos fascículos (in)dependientes $^{31}$, como reflejan sus signaturas de cuaderno, que se recogen en la primera mitad más una de sus hojas, aunque con alguna omisión puntual en ambos impresos $^{32}$, y que dan lugar a la siguiente estructura colacional ${ }^{33}$ :

\section{Qüestión de amor ${ }^{34}$ \\ Cárcel de amor}

$$
\begin{aligned}
& \mathrm{A}^{8}, \mathrm{~B}^{4}, \mathrm{C}-\mathrm{N}^{12}\left[\mathrm{~A}^{\mathrm{v}+3} \mathrm{~B}^{\mathrm{iji}+1} \mathrm{C}-\mathrm{N}^{\mathrm{vij}+5}\right] \\
& \mathrm{A}-\mathrm{H}^{12}\left[\mathrm{~A}-\mathrm{H}^{\mathrm{vij}+5}\right]
\end{aligned}
$$

A pesar de que las formas se componen siempre en dozavo, no todos los cuadernos son de 12 hojas, puesto que la tira del pliego, con cuatro, no se incorpora al cuaderno A, que, así, queda formado de ocho hojas, sino que daría lugar a un cuaderno B, a diferencia del resto de pliegos, que generan cuadernos de seis bifolios concéntricos ${ }^{35}$. Esta práctica de imposición de las formas en dozavo responde a una de las cinco de la imprenta antigua, en concreto a

${ }^{30} \mathrm{He}$ utilizado para mi descripción y estudio tanto el ejemplar de la de la Österreischische Nationalbibliothek de Viena, como el de la Biblioteca Nacional de España, si bien solo he consultado directamente este último, mientras que, para el primero, me sirvo de la digitalización en línea.

${ }^{31}$ Ambos impresos, en cualquier caso y como hemos visto, forman una edición conjunta a partir de la llamada a la Cárcel de amor y, así, a la unidad del volumen que hace la portada de la Qüestión de amor; de ahí el juego de los paréntesis, puesto que este modelo editorial combina ambos aspectos para su rentabilidad comercial y no se contradice, por tanto, la dependencia de las portadas y la independencia de las signaturas de cuaderno. De esta concepción unitaria escapa, sin embargo, la venta exenta de la segunda de las obras, sin duda prevista desde su concepción como producto editorial.

${ }^{32}$ En el impreso de la Qüestión de amor, faltan las signaturas Cvj y Dvj, mientras que en Hvij no se incluye la letra de cuaderno, sino exclusivamente el número, separando la $v$ de la las $i j$. Por lo que respecta a la Cárcel de amor, faltan las signaturas Evij y Fvij, y hay un error en Gvij, de la que se omite la $v$ y se representa como Gij.

${ }^{33}$ Que he comprobado directamente a partir del ejemplar de la Biblioteca Nacional de España, con signatura R/39980, al que le faltan, sin embargo, las hs. G1 y G12.

${ }^{34}$ Jean F. Peeters Fontainas, L'officine espagnole de Martin Nutius à Anvers, Amberes, Societé des Bibliophiles Anversois, 1956, p. 36, n. ${ }^{\circ}$ 9, indica, para el impreso de la Qüestión de amor, la estructura colacional A-N $\mathrm{N}^{12}$, mientras que debe de advertir que, con ello, se está computando un pliego en dozavo de más, por lo que, una década después, opta por la fórmula $\mathrm{A}^{8}, \mathrm{~B}^{4}, \mathrm{C}-\mathrm{N}^{12}$, fiel a las signaturas y, sobre todo, al plegado independiente de los dos primeros cuadernos, Jean F. Peeters Fontainas, Bibliographie des Impressions Espagnoles des Pays-Bas Méridionaux, 2 vols., Nieuwkoop, B. de Graf, 1965, pp. 595597, n. $^{\circ} 1162$.

${ }^{35}$ Como he podido comprobar a partir del original de la BNE (R/39980), encuadernado en pergamino y en cuyo lomo se indica «Question / de Amor / Y / Carcel de / Amor». Hay muchas anotaciones en la portada de la Qüestión de amor y en la última hoja en blanco de la Cárcel de amor, que tienen que ver con antiguos propietarios: alguna de las primeras relaciona el ejemplar con el «Convento de S. Andres» y las segundas con contextos italianos. Su análisis resultaría muy interesante si el objeto de este trabajo fuesen los ejemplares concretos, pero no es así y debe quedar relegado su análisis. Este ejemplar llegó a la BNE muy recientemente, en 1998, mediante compra a la Llibreria Antiquària Delstres, de Barcelona, como nos indica la información adicional del catálogo en línea de la BNE. 
la tercera de las que explica Alonso Víctor de Paredes ${ }^{36}$, la del dozavo con tira, si bien solo prevé la posibilidad de que las cuatro hojas de la tira se incorporen en medio del doblado de las otras ocho y no como cuaderno independiente, algo que sí que encontramos en el manual decimonónico de Sabrel: «el cuadernito se encaja ó no en el mayor, según lo manifiesta la signatura» ${ }^{37}$.

En los dos impresos de esta edición de obras sentimentales se marca la signatura hasta la primera hoja de la segunda mitad del cuaderno, aunque llama la atención que en este cuaderno B de la Qüestión de amor, en lugar de la signatura $\mathrm{Bij}$, encontremos Avj, un error que evidencia una cierta torpeza en el proceso de composición. La página con las signaturas B y Biij pertenecen al blanco, mientras que [Bij] formaba parte de la retiración. Si tenemos en cuenta que la retiración se compone antes que el blanco en la imprenta hispánica y, a la luz de lo ocurrido aquí, debía de funcionar igual en la flamenca, la página con la signatura Avj se compuso antes, en una forma que no contenía las hojas Br y Biijr, las únicas del cuadernillo derivado de la tira que, en la versión final, contienen esta letra. En un principio, por tanto, se habría previsto la formación de un cuaderno A con la tira concéntrica plegada y cosida en el centro del cuaderno mayor. En la posterior composición del blanco es donde se generó la disfunción y, como así lo indicaban la mayoría

\footnotetext{
${ }^{36}$ «GÉNERO IMPERFECTO. Llamé al primero Género perfecto, porque el pliego en aquellas imposiciones se dobla perfectamente, como èl va pidiendo: no asi en estas que se dobla de otro modo diferente, como se verà por las signaturas, y por esso lo llamo imperfecto. Sus planas son mas largas que lo acostumbrado, sin duda para poder traer los tales libros de faltriquera. Sus imposiciones son cinco, aunque las dos primeras tienen una misma colocacion de planas. La primera es dozavo, doblādo todo el pliego sin partir tira. La segunda es dozavo con tira, esto es, cortando la tercera parte del pliego, por donde en los diseños pusiere yo vna raya, y aviendolo cortado, las ocho hojas que quedan se doblā como pliego de à octavo, y en medio destas ocho hojas se ponen las obras (sic) quatro, doblandolas de forma, que salga en lugar de la primera la que fuere nueve, que se conocera por la signatura de A 5. Y esta tira se parte siempre en las imposiciones de veinte y quatro, y quarenta y ocho. La tercera es dozavo sin cruzero en la rama, y se tira con tres punturas. La quarta es veinte y quatro, que tiene dos dozavos, cuyas primeras van a la cabeça, la de $\mathrm{A}$ al segundo tiro, que mira su reclamo à la esquina de la tabla, y la de $\mathrm{B}$ al primero, arrimada al cruzero, $\mathrm{y}$ las tiras azia el pie de la forma. La quinta es quarenta y ocho, que tiene quatro dozavos, la primera de $\mathrm{A}$ al primero tiro, arimada à la mitad del cruzero; la de $\mathrm{B}$ al segundo tiro, pegada à lo alto del cruzero, la de $\mathrm{C}$ en el mismo tiro segundo, arrimada a la mitad del cruzero; la de $\mathrm{D}$ al primer tiro, al pie del cruzero; $y$ las tiras de todas van àzia los hierros de lado, que se dividen por donde pongo las estrellas», Alonso Víctor de Paredes, Institución y origen del arte de la imprenta y reglas generales para los componedores, ed. Jaime Moll, Madrid, Calambur, 2002, pp. 32v-33r.

${ }^{37} \mathrm{M}$. Sabrel, Manual completo del encuadernador, teórico y práctico, Barcelona, Hijos de Francisco Sabater, $1911^{4}$, p. 22. «El pliego en dozavo contiene 24 páginas á 12 hojas. No es posible al imprimirlo disponer las páginas de manera que con simples pliegues, como se hace en el octavo, se pueda plegar el pliego por entero. Es necesario cortar, pues, una tira que contiene ocho páginas, la que se dobla aparte, y formar de ella un pequeño cuaderno, el que se llama así, pues de lo contrario formaría cuadernos demasiado voluminosos muy difíciles de encuadernar y poco sólidos. Lo demás del pliego se dobla como el octavo, formando un segundo cuaderno que contiene 16 páginas, el que se llama cuaderno mayor», ibidem, p. 20.
} 
de las signaturas, se acabó plegando como un cuaderno independiente de cuatro hojas, una práctica que, en cualquier caso, no era desconocida en la imprenta antigua.

A ello habría contribuido la existencia, en última instancia, de un antígrafo con cuadernos de 8 hojas, plegados en $8^{\circ}$ o formados por dos pliegos en $4^{\circ}$. En esta misma línea de contaminación por rasgos de su original, se encontraría el uso de numeración romana en las signaturas, en vez de arábiga, que sería la esperable al tratarse de un impreso con letra redonda-como ocurre, por ejemplo, en las diferentes ediciones del Cancionero de romances de Nucio-, lo que, por tanto, apuntaría a un antígrafo en letra gótica ${ }^{38}$. La medida de 20 líneas corresponde a $78 \mathrm{~mm}^{39}$, como habríamos tenido también en la princeps de Boscán y Garcilaso. Este rasgo tipográfico y la formación de cuadernos de ocho hojas, unido al estudio ecdótico de la Qüestión de amor, podría llegar a determinar la fuente de Nucio, lo que, en cualquier caso, debo relegar a otro trabajo, pues sobrepasa los objetivos de este.

Las filigranas se encuentran en el corte vertical y, regularmente, en las hs. 7-8 u 11-12 de cada cuaderno, excepto en el cuaderno A, que no las contiene, y en el cuaderno B, que las presenta en las hs. 3-4, lo que se justifica al provenir ambos de un mismo pliego y habiendo quedado en la tira la marca de agua. La filigrana es un jarrón de una sola asa, con dos diseños, que varían en las decoraciones internas, sobre todo. Todos los cuadernos recogen, sistemáticamente, un modelo u otro de esta filigrana, a excepción del cuaderno D de la Cárcel de amor, en el que se trata de una mano enguantada, de dedos cerrados y con estrella de cinco puntas.

La marcación de los cuadernos es independiente en ambos impresos ${ }^{40}$, lo que, sin duda, está al servicio de la estrategia editorial de Nucio en esta edición conjunta, como también lo está la ausencia de paginación propiamente dicha. En la edición de Martín Nucio de 1556, las signaturas de cuaderno de la Cárcel de amor son ya continuación de las correspondientes a la Qüestión de amor, según la estructura colacional A-R ${ }^{12}$, y así arraiga en la edición de Philippo Nucio de 1576, mientras que en la de Martino Nucio de 1598 se vuelve a las signaturas independientes $\left(\mathrm{A}-\mathrm{I}^{12}, \mathrm{~A}-\mathrm{F}^{12}\right)$ y se incorpora la

\footnotetext{
${ }^{38}$ Agradezco a Mercedes Fernández Valladares que me advirtiese este matiz material de las signaturas y que me ayudase a representar la estructura colacional de la Qüestión de amor, coincidente con la de Peeters Fontainas, Bibliographie des Impressions..., ob. cit., pp. 595-597, n. ${ }^{\circ}$ 1162. Si algún rasgo material no se hubiese plasmado en este trabajo como correspondería, atribúyase a mi torpeza y no a las generosas indicaciones de mi colega.

${ }^{39}$ En ambos impresos, tomada en la Qüestión de amor de Avjr y en la Cárcel de amor de Ciijr, y confirmada en otras pruebas.

${ }^{40} \mathrm{E}$, incluso, el de la Cárcel de amor inicia el Tratado de Nicolás Núñez en un nuevo pliego.
} 
paginación -que acaba al final de la Cárcel de amor-, también particular para cada obra y con la peculiaridad de que las págs. 136-148, con los poemas añadidos desde 1556, quedan sin numeración:

\author{
EDICIONES $^{41}$ \\ Martín Nucio, 1546 \\ Martín Nucio, 1556 \\ Philippo Nucio, 1576 \\ Martino Nucio, 1598
}

ESTRUCTURA COLACIONAL
$\mathrm{A}^{8}, \mathrm{~B}^{4}, \mathrm{C}-\mathrm{N}^{12}, \mathrm{~A}-\mathrm{H}^{12}$
A-R $^{12}$
A-R
A-I
12
A-F ${ }^{12}$

Paginación

No

No

No

$1-221,1-135$

Las nuevas ediciones salidas de los talleres nucianos durante el siglo XVI evidencian, a través de estos rasgos, que el modelo editorial y, con ello, comercial ha cambiado, sin duda por el éxito del producto conjunto, reproducido por otros impresores, ya desde los Caldera en 1548. Más allá de las imitaciones de otros, las reediciones nucianas y su evolución hacia una edición de ambas obras como un solo impreso son buena prueba del éxito comercial de la iniciativa de Martín Nucio en la princeps de 1546, que, una vez testada en el mercado, podía unificarse.

La Qüestión de amor de 1546 es un impreso formado de 144 hojas, mientras que la Cárcel de amor cuenta con 96 hs., lo que supone un total de 240 hs. para la editio princeps de este volumen formado por dos impresos. Está plegado en $12^{\circ}$, como se advierte también de la colación de cuadernos y, por la horizontalidad de los corondeles ${ }^{42}$, sabemos que es un dozavo común y no prolongado.

Es frecuente que se destaque la primera ocasión en que aparece un formato determinado al hablar de la tradición editorial de las obras concretas, como ha sido el caso, por ejemplo y en cuanto al dozavo, de La Celestina, de la Cárcel de amor, del Lazarillo de Tormes o del Cancionero de romances, pero, además, conviene contextualizarlo en la historia del taller de imprenta que innova al respecto. Así, este formato:

\footnotetext{
${ }^{41}$ Si bien solo hay un ejemplar de la princeps en la BNE, sí se conservan otros del resto de ellas, que también he podido consultar directamente: de la edición de 1556 tenemos tres, con las signaturas $\mathrm{R} / 1998(2)$, R/9192 y R/13601; dos de 1576, con signatura R/30476 y U/752; dos de 1598, una completa (R/7105) y, por separado, las secciones del impreso, en R/1998(1) la Qüestión de amor y en R/7612 la Cárcel de amor. El facticio R/1998 reúne la la Qüestión de amor de 1598 y la Cárcel de amor de 1556. Algunos de estos ejemplares están en la Biblioteca Digital Hispánica, aunque no el de la princeps, ni la Qüestión de amor de 1556: 1556, R/1998(2); 1576, U/752; y 1598, completo en R7105 y desgajadas las secciones en R/1998(1) y R/7612.

${ }^{42} \mathrm{La}$ distancia entre un corondel y otro es muy sistemática, de $20 \mathrm{~mm}$, como he podido comprobar en el ejemplar de la BNE.
} 
no había sido extraño a las prensas de Nucio, sino todo lo contrario: como se puede concluir de una revisión al catálogo de Peeters Fontainas (1956), hay hasta sesenta y ocho obras impresas por Martín Nucio en $8^{\circ}$, veintitrés en $12^{\circ}$ e, incluso, dos en $16^{\circ}$. Frente al interés por estos formatos tan manejables, sólo están in folio tres de las ciento una obras en español que salieron de sus prensas y únicamente encontramos cuatro en $4^{\circ}$. Son datos que evidencian la voluntad de Martín Nucio por imprimir obras en español en tamaños de faltriquera, que potenciaran un precio popular, facilitando, así, su venta y difusión. De hecho, explicita esta voluntad de mercado en el prólogo a su primera edición del romancero de Sepúlveda, refiriéndose a su Cancionero de romances de 1547-1548: «Como yo avía tomado los años passados el trabajo de juntar todos los Romances viejos (que avía podido hallar) en un libro pequeño y de poco precio» ${ }^{43}$.

En las obras de Boscán y Garcilaso, impresas en diciembre de 1544, Martín Nucio usó por primera vez el formato en dozavo, muy probablemente por tratarse de una edición de poesía, de manera que se aprovechase mejor el papel reduciendo su caja de escritura ${ }^{44}$. Al descubrir con ello los enormes beneficios de portabilidad y precio de sus impresos, el formato acabó adaptándose a obras en prosa de no demasiada extensión, como esta edición conjunta de la Qüestión de amor y de la Cárcel de amor. A ello añade Alejandro Higashi un aspecto que me parece esencial: «la identidad de la publicación estaba salvaguardada frente a sus posibles modelos y competidores $\rangle^{45}$. No solo se singulariza, por tanto, frente a la tradición previa, con un nuevo formato editorial, que conlleva ciertos alicientes - portabilidad y precio-, sino que los impresores parisinos Hernaldo y Claudio Caldera dejan una huella clara de su apropiación en su edición en dozavo, de 1548, y quizás ${ }^{46}$ presenta un formato aun menor en la del impresor salmantino Lasso de la Vaca; u otros, como Esteban de Nájera en 1551, que son más sutiles en su imitación, pero igualmente dependientes, a pesar de ser una clara competencia de mercado.

\footnotetext{
${ }^{43}$ Josep Lluís Martos, «El público de Martín Nucio: del Cancionero de romances al Cancionero general de 1557», en Convivio. Cancioneros peninsulares, ed. de Vicenç Beltran y Juan Paredes, Granada, Universidad de Granada, 2010, pp. 111-123, pp. 113-114.

${ }^{44}$ Josep Lluís Martos, «La fecha del Cancionero de romances sin año», en Edad de Oro, 36 (2017), pp. 135-155, pp. 140-141.

${ }^{45}$ Alejandro Higashi, «El género editorial y el Romancero», en LEMIR, 17 (2013), pp. 37-64, p. 49.

${ }^{46}$ No he podido consultar el ejemplar único de la edición salmantina de Pedro Lasso de la Vaca (1580), en la biblioteca privada de José Luis Gotor, que Marín Pina, art. cit., p. 157, no incluye entre los ejemplares en dozavo y del que «en el Catalogue d'une partie des livres de la bibliothèque du Cardinal de Loménie de Brienne, Paris, chez Mauger, Libraire, 1797, se registra [...] in-18» (Comedic, ob. cit.).
} 
La caja de escritura está formada por 25 o 26 líneas $(100 \times 50 \mathrm{~mm})^{47}$, en los dos impresos, además de una línea extra que acoge la signatura de cuaderno y los reclamos. Estos últimos son sistemáticos en todas las planas, para su casado en las formas, de manera que se asegure la correcta sucesión de los cuadernos. Presenta, además, titulillos complementarios -partiendo en dos el nombre de la obra ${ }^{48}$ - en el vuelto de una hoja y en el recto de la siguiente, puesto que se corresponde a la unidad de conformación de lectura u opening. Sin embargo, estos titulillos desaparecen en la última sección, en la que se incorporan los romances que rematan el último pliego, lo que no deja de ser sintomático.

Como marca de principio de párrafo, en general, se utilizan calderones, mientras que el inicio de los epígrafes presenta una inicial lombarda impresa, de tres líneas y en arracada. Los únicos grabados de esta edición son los correspondientes a las marcas de impresor y a las capitulares, a los que dedico epígrafes independientes por su repercusión en la datación y en la estructura interna de esta edición.

\section{Las marcas de impresor y la datación de los impresos}

Peeters Fontainas estudia las obras salidas de las prensas de Martín Nucio a partir de los grabados con su marca de impresor, siete de los cuales presentan la imagen de las dos cigüeñas ${ }^{49}$, mientras que el octavo reproduce la de un unicornio. La primera y más longeva de estas marcas se incorpora por primera vez en 1544, a la cual añade, después, el lema de su divisa: «Pietas Hominis Tvtissima Virtvs». La matriz se va desgastando con el uso y acaba generando tres defectos, lo que es un hecho, por su sistematicidad, más allá de ligeros problemas de entintado, que deben revisarse, en cualquier caso, pues podrían aportar matices a la cronología de Peeters Fontainas ${ }^{50}$.

La Summa de Doctrina Christiana de Constantino Ponce de la Fuente aún se cataloga con dos defectos, con el problema de ser el único con esta circunstancia y con la mala suerte de que se imprime sin año. Peeters Fontainas

\footnotetext{
${ }^{47} \mathrm{He}$ tomado las medidas del ejemplar de la BNE y he comprobado el dato en los primeros cuadernos de ambos impresos.

${ }^{48}$ Además de algunos titulillos para los paratextos: PROLOGO o EL PROLOGO, EL ARGUMENTO o COMIENZA LA OBRA. Este último caso, en h. aiiijr, genera una disfunción, ya que en la h. aiijv aparece el titulillo QVESTION, pero en la página siguiente, por tanto, no se completa con DE AMOR.

${ }^{49}$ Peeters Fontainas, L'officine espagnole..., ob. cit., pp. 19-32. «Le mâle apportant un poisson à sa compagne, pour les trois premières, et un anguille, pour les suivantes» (ibidem, p. 19).

${ }^{50}$ Los defectos existen y son, a mi parecer, indiscutibles, pero el alcance de su desgaste es, en ocasiones, algo menor en ediciones posteriores y este dato debe ser observado y evaluado.
} 
sugiere datarlo en $1549^{51}$, de manera que, si realmente fue así, se habría generado pronto el tercero de los desgastes, porque ya lo presentan todas las obras con esta marca impresas a partir de $1550^{52}$. La segunda edición nuciana del Cancionero de romances es, en cualquier caso, uno de los dos únicos impresos de 1550 expresamente datados y, frente a su grabado, el de los Romances de Sepúlveda (c. 1551) $)^{53}$ presenta un deterioro mayor de los tres defectos de esta marca ${ }^{54}$, que no se tiene noticia de que se vuelva a utilizar hasta una edición en francés de $1555^{55}$ :

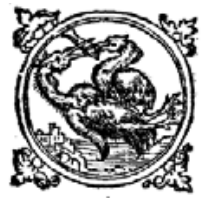

Obras de Boscán y Garcilaso 1544

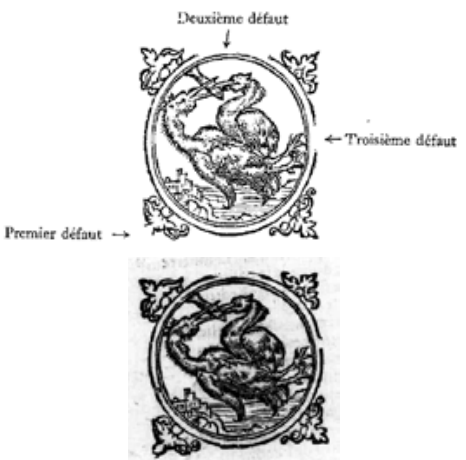

Cancionero de romances 1550

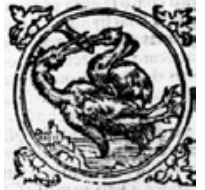

Romances de Sepúlveda c. 1551

Al clasificar los impresos a partir de la ausencia o la acumulación de desgastes en esta marca de impresor y teniendo en cuenta los datos fehacientes que suponen las ediciones que sí que están fechadas, como, precisamente, es el caso de la que reúne la Qüestión de amor y la Cárcel de amor, Peeters

${ }^{51}$ En su entrada individualizada, Peeters Fontainas, L'officine espagnole..., ob. cit., p. 44, n. ${ }^{\circ} 26$, porque en el listado de impresos con errores de la primera marca data esta edición en «1549/50» (ibidem, p. 21).

${ }^{52} \mathrm{Si}$ es que, realmente, todos aquellos que Peeters Fontainas, L'officine espagnole..., ob. cit., p. 21, cataloga en ese año, a pesar de no presentar fecha, fueron impresos entonces.

${ }_{53}$ Único e incorporado a la portada, pues el texto de los romances acaba en el vuelto de la última hoja del último cuaderno y, a diferencia de otros impresos salidos de este taller, no se cierra el volumen con el grabado de Martín Nucio.

${ }^{54} \mathrm{E}$, incluso, podríamos hablar de un cuarto error en la parte inferior del círculo externo, que ya tiene algún problema de entintado en los cuatro grabados de la edición de la Qüestión de amor y de la Cárcel de amor, con problemas en el Cancionero de romances de 1550 y en los Romances de Sepúlveda.

${ }^{55}$ Este impreso aún presentaría los tres defectos del taco en la contraportada, pero, según Peeters Fontainas, están restaurados en el escudo de la portada, lo que, sin duda, habría que comprobar en el original, por su extrañeza, ya que podría tratarse de una intervención manual y puntual: «Une fois encore en 1555, Nutius se sert de cette marque; il imprime, pour compte du libraire Jehan de la Forge, de Tournai, "Les Coustumes, Stilz, et Usaiges de l'Esschevinage de la Ville de Tournay". La marque est grossièrement restaurée, du moins telle qu'elle apparait sur la page de titre, alors qu'au dernier feuillet elle se présente avec les trois défauts qui la caractérisaient en 1551», Peeters Fontainas, L'officine espagnole..., ob. cit., p. 21. 
Fontainas elabora un catálogo cronológico de las obras salidas de las prensas de Martín Nucio entre las fechas en que se produce tal deterioro ${ }^{56}$. Se limita, sin embargo, a este listado de impresos ordenado por horquillas temporales, sin que nada justifique la secuencia interna de cada una de las secciones y sin aportar otros matices de conjunto o particulares de cada una de ellas. Es en esta línea de acción que se ha podido precisar la fecha de la editio princeps del Cancionero de romances, cuyo proyecto habría que datar en $1546^{57}$, el mismo año en que se imprime la edición conjunta de la Qüestión de amor y de la Cárcel de amor, como sabemos por la portada de la primera, aunque sin especificar más datos al respecto, ni repetirse este en la segunda.

El grabado de esta primera marca de impresor de Martín Nucio, que se empieza a utilizar en 1544, aparece sin defectos por última vez en una edición de 1546, precisamente en la Qüestión de amor, aunque solo en el de la portada, puesto que su grabado final ya presenta un ligero desgaste, que se intensifica en el inicial de la Cárcel de amor, para cobrar su estado defectuoso definitivo en el que la remata. He podido comprobar la coincidencia de estos defectos tanto en el ejemplar de la Österreischische Nationalbibliothek de Viena, como en el de la Biblioteca Nacional de España, de manera que no estamos ante una mera cuestión de entintado. El proceso de degradación de la matriz se genera, por tanto, durante la impresión de esta edición conjunta y se puede apreciar claramente a través de sus cuatro grabados:

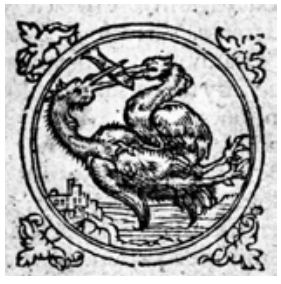

Qüestión de amor, $\mathrm{A} 1 \mathrm{r}$

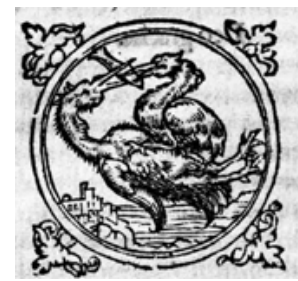

Qüestión de amor, $\mathrm{N} 12 \mathrm{v}$

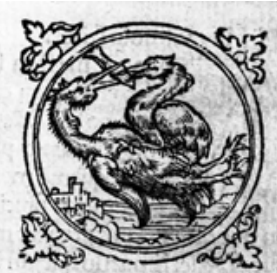

Cárcel de amor, A1r

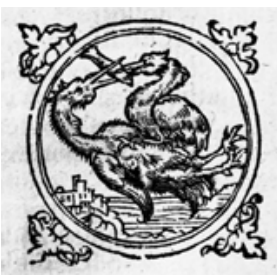

Cárcel de amor, $\mathrm{H} 12 \mathrm{v}$

Si tenemos en cuenta que, entre seis y ocho impresos de $1546^{58}$ reproducen esta marca de impresor ya desgastada, habría que concluir, sin lugar a dudas, que la edición de la Qüestión de amor y de la Cárcel de amor, durante

${ }^{56}$ Peeters Fontainas, L'officine espagnole..., ob. cit., pp. 20-21.

${ }^{57}$ Martos, «La fecha...», art. cit.

${ }^{58} \mathrm{La}$ impresión y/o indecisión de los datos proviene, en última instancia, de la propuesta de datación del Oratorio de Guevara (n. $\left.{ }^{\circ} 15\right)$ y de las Obras de Boscán y Garcilaso (n. $\left.{ }^{\circ} 19\right)$ en una horquilla de fechas, entre 1546 y 1547, por parte de Peeters Fontainas, L'officine espagnole..., ob. cit., pp. 21 y 39-41. 
la cual se daña la matriz, debió de ser en los primeros meses de ese año ${ }^{59}$, teniendo en cuenta, además, que la impresión de ambos fascículos no se habría distanciado más que unos días o unas semanas, a la luz de lo que he explicado anteriormente sobre esta práctica editorial.

\section{La morfología de las capitulares}

La edición incorpora tres capitulares impresas ornadas, lo que, a pesar de su aparente limitación, contrasta positivamente con la aparición de una sola tanto en la edición de 1544 de las obras de Boscán y Garcilaso, como en las ediciones del Cancionero de romances, cuya matriz de la editio princeps parece que reutiliza Nucio, aunque muy desgastada, en 1550, mientras que la cambia en la siguiente, a pesar de salir aún de su taller en 1555, como ocurre también en 1568 con la de su hijo Philippo y, lógicamente, en la de Lisboa de 1581:

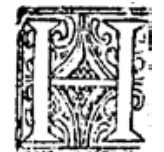

Obras de Boscán y Garcilaso 1544

h. $60 \mathrm{r}$

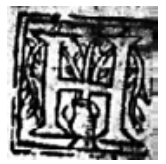

Cancionero de romances 1555 h. A1v

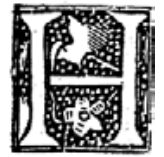

Cancionero de romances 1546

h. A3r

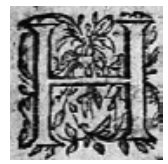

Cancionero de romances 1568 h. A1v

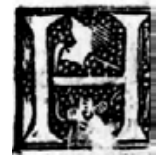

Cancionero de romances 1550

h. A1v

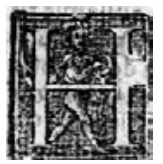

Cancionero de romances 1581 h. A1v

En la edición que nos ocupa, las tres capitulares impresas corresponden, en realidad, a dos únicas matrices, pues da la casualidad de que una de ellas se repite:

\footnotetext{
${ }^{59}$ Con tiempo suficiente para que, si fue el caso, hubiese influido en la edición de Medina del Campo de 28 de febrero de 1547, que sigue la estrategia de agrupar la Cárcel de amor a otras obras sentimentales, aunque aquí primando la unidad de autor, alejándose del producto salido de las prensas de Nucio por razones comerciales, como novedad editorial que lo distinga de aquel.
} 


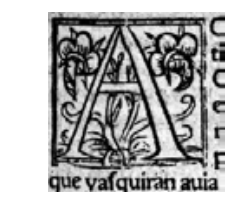

Qüestión de amor, $\mathrm{A} 4 \mathrm{r}$

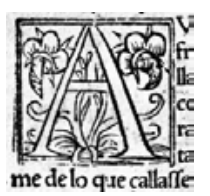

Cárcel de amor-San Pedro, A1v

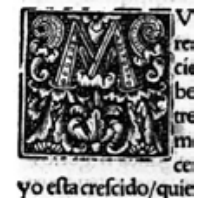

Cárcel de amor-Núñez, G1r

Se incorporan en arracada y alcanzan la medida de seis líneas de escritura, en el primer caso, y de siete en el segundo, aunque queda una separación mayor entre el grabado y la línea siguiente ${ }^{60}$. En cualquier caso, es evidente que la matriz de la $M$ es ligeramente más grande que la de la $A$, pero lo es aún más que pertenecen a dos juegos diferentes. La primera de estas capitulares es hueca, con fondo blanco y con diseños exclusivamente vegetales, que no se entrelazan con la letra, sino que esta se superpone, mientras que la segunda decora el interior de la inicial con remaches que recuerdan el forjado, combinados con vegetación y con fondo negro, punteado en blanco, a la manera de la $H$ capitular del Cancionero de romances de 1546 y 1550 , que, en cualquier caso, es mucho menos elaborada.

Sí que he podido localizar, sin embargo, un nuevo uso de la matriz de la capitular $A$ en otro impreso de Martín Nucio, seis años posterior a esta edición de obras sentimentales, encabezando el texto del Laberinto de Fortuna en las Obras de Juan de Mena de 1552:

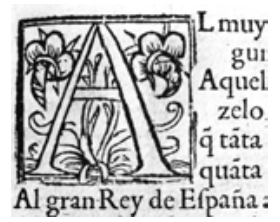

Obras de Juan de Mena, h. 4r

Esta no es la única de las capitulares ornadas de esta edición de Mena impresa por Nucio, pero, en cualquier caso, comparte con la edición de 1546 tanto su escasez, como su heterogeneidad. Y es que ambos rasgos caracterizan los impresos de formatos menores de Martín Nucio, que no debemos idealizar, desde nuestros intereses científicos, e interpretar desacertadamente fuera de un modelo de producción comercial que está muy lejos de lo que encontramos en obras como el Orlando furioso de 1549, traducido por Urrea ${ }^{61}$.

\footnotetext{
${ }^{60}$ Es por esto que he incorporado los límites del texto en las imágenes y lo haré, después, en la capitular de las Obras de Juan de Mena de 1552.

${ }^{61}$ Una obra con un rico juego de capitulares y con un programa iconográfico cuidado, con cuarenta y cinco grabados de escenas muy desarrolladas, que inauguraban cada uno de los cantos. Se debió de 
En el caso de las ediciones de las Obras de Boscán y Garcilaso, del Lazarillo de Tormes, de la Celestina o de la que aquí nos ocupa, con la Qüestión de amor y la Cárcel de amor, entre otras, estamos ante otro tipo de producto: se trata de alta cultura medieval difundida por Nucio mediante producciones económicas y de faltriquera, una literatura puesta en odres nuevos y no en vano se destaca su dozavo o, incluso, el novedoso octavo para algunas obras ${ }^{62}$. En estos productos, el mero hecho de utilizar capitulares ya supone un cierto ennoblecimiento, pero no esperemos que sea un recurso ornamental recurrido o que los tacos se elaboren ex professo, de manera que nos encontraremos con series diferentes y/o con matrices desgastadas. No lo esperemos, porque, con ello, Martín Nucio reduce los costes y porque, en consecuencia y en definitiva, es un rasgo material definitorio de estas ediciones de faltriquera.

\section{Los conectores tipográficos y la estructura interna de la edición}

Las capitulares impresas no solo nos aportan datos sobre un producto editorial a partir de su morfología, sino que cumplen la función de organizadores textuales del impreso, como recurso que ordena sus contenidos y permite reconocer fácilmente su estructura, por un rápido enfoque visual. Establecen un rango sintáctico superior entre las secciones de esta edición, en la que su limitado número, más allá de criterios económicos de producción y venta, responde a la estructura tripartita de este producto bibliográfico nuciano. Así, como se ha visto en el epígrafe anterior, se utilizan para iniciar la Qüestión de Amor, la Cárcel de Amor y el Tratado de Nicolás Núñez. Con ello, esta última obra mantiene la singularidad textual que presentaba en su tradición editorial anterior ${ }^{63}$, a pesar de ser una suerte de continuación de la obra de San Pedro y de que haya otros rasgos que apunten a la unidad conceptual

\footnotetext{
encargar, en su totalidad y en su complejidad, a Arnold Nicolai, el grabador de las ediciones del impresor veneciano Gabriel Giolito, cuya edición de 1542 se imita en esta de 1549, preparada para ser entregada al entonces príncipe Felipe a su llegada a Amberes. Para este tema, véase Martos, «La fecha...», art. cit., pp. 144-149.

${ }^{62} \mathrm{Y}$ es que las mismísimas Obras de Juan de Mena de 1552 responderían a este modelo comercial del producto impreso.

${ }_{63}$ «En su larga trayectoria editorial, la Cárcel de amor pocas veces se publica sola. Muy pronto, en 1496, se suma a ella la continuación de Nicolás Núñez [...]. En las ediciones antiguas hasta ahora conocidas, siempre se imprime tras la Cárcel de amor, respetando la independencia de ambos textos y su correspondiente autoría. En todas ellas, el texto de Núñez cuenta con su propio título, a veces incluso con su propia portada ilustrada $(1542,1551)$, o bien se marca la transición entre ambas piezas con espacios en blanco o cambios de página. Sin embargo, no siempre se anuncia en la portada principal y así / sucedió la primera vez que vio la luz en 1496. Silenciado en el título general, quizá por su incierta recepción, tuvo que ser una sorpresa para el público del momento encontrarse inesperadamente al final de su lectura con este pequeño tratado», Marín Pina, art. cit., pp. 164-165.
} 
entre ambas, como la rúbrica de fin de obra o la ausencia de referencia en la portada o tabla inicial.

Recursos como este ennoblecen los impresos, porque forman parte de su decoración, pero lo hacen «en estrecha relación con la tipografía» ${ }^{64} \mathrm{y}$, de ahí, que tengan su función macrotextual en los impresos. El estudio morfosintáctico de las capitulares grabadas debe hacerse en paralelo a otros recursos tipográficos, que, en general, suponen una tipología particular de conectores discursivos. El análisis de estos organizadores tipográficos y su función en la imprenta antigua nos permite avanzar en el conocimiento de ediciones concretas e, incluso, nos podría llegar a generar datos sobre el proyecto editorial en cuestión y su desarrollo en el propio taller ${ }^{65}$.

En esta edición de 1546, Martín Nucio es bastante sistemático en su jerarquización estructural mediante el uso de ciertos conectores tipográficos, que hacen emerger y reconocer fácilmente la estructura interna del libro. Establece tres rangos y funciones diferentes: las capitulares grabadas, las iniciales lombardas y los calderones, que marcan, respectivamente, el inicio de las tres obras principales, de los epígrafes y de los párrafos o rúbricas. Estos, sin embargo, no son los únicos organizadores tipográficos de la edición, sino que encontramos otros que encabezan y cierran las obras, para los que en el taller de Nucio no se aplicó tanta sistematicidad como en los tres recursos anteriores. En cualquier caso, su función iniciática o conclusiva se reconoce con facilidad, al ser rasgos muy visuales y al haberse utilizado a este fin en otros productos editoriales e, incluso, codicológicos desde hacía décadas. Lo que interesa de su análisis es, por tanto, su repercusión en la estructura interna del impreso, así como su falta de regularidad, como huella material que permitiese reconstruir los avatares de su proceso editorial.

No volveré ahora ni a las portadas de ambos impresos, ni a los grabados con el escudo del impresor, ni a la coincidencia material entre el inicio de obras y cuadernos, a pesar de su función como organizadores de la edición, evidente a partir de lo tratado en los epígrafes anteriores, sino que me centraré en las rúbricas principales y en las de cierre, como delimitadoras textuales, cuya estructura sinóptica es la siguiente:

${ }^{64}$ Ronald B. McKerrow, Introducción a la bibliografia material, Madrid, Arco Libros, 1998, p. 37.

${ }^{65}$ Para esta metodología de análisis, limitada entonces al análisis morfosintáctico de las capitulares, véase Josep Lluís Martos, «Un incunable de Pere Trincher: tipografía, decoración y datación», en Revista de poética medieval, 30 (2016), pp. 199-231, donde se desarrolla por primera vez y se aplica a un incunable valenciano. 
Qüestión de amor

COMIENCA LA OBRA.

h. A4r

\section{IEL SIGVIENTB \\ TRATADOFVEHECHO a pedimiento delféior don diego her nandez/alcaydedelosdonzelles/y de \\ los otros caualleros cortefanos. \\ Ellama fecarcel de amor / cỏ \\ pufolodiego de fan pe: \\ dro.Comienca el prologo affi.}

h. A1v

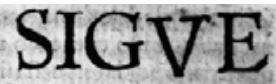

SE EL TRATADO QVE.

hizo Nicolas nuñez fobre el que die: godefant pedro compufo déle

riano y laureola:llamado carcel de amor.

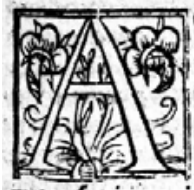

h. $\mathrm{A} 4 \mathrm{r}$

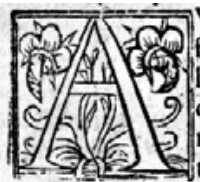

h. A1v
Cacfcio pues ă al tiempo que eirey Carlos de Francia entro é ycalia y gas noelreyno de $\mathrm{Na}$ que vafquiran auia nombre de naciō Efpañola narural delaciudad de To. domir:andando enla corte del ferenif

Cárcel de amor-San Pedro

Ynque me falta fu frimiento para cas llar / no me fallece conofcimiento pas raver quantomeef me de lo que callaffe ; que arrepétir me de lo que dixefle. E puefto queaffilo conozca/avn que veo la verdad/ figo

Cárcel de Amor-Núñez

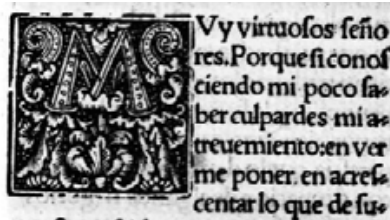
yo eftacrefcido/quiero(fipudiere) mi defcargo fatifhazerloğ hize/avns

h. G1r

h. G1r

Poemas de remate
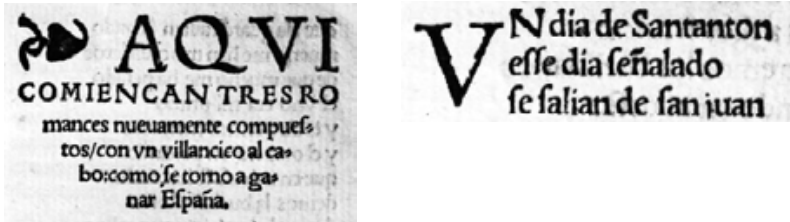

Aquife acaba el carcelde amor.

ISis ouicra pormal perderel fefo por pers der el penfamiento dellas.Peromem brando mecomo no auia ningun pro uecho penfar mas enello/trabajauaco migoquanto podia porme defender decraellas alamemoria.Y affitrabaian doelcuerpo enel camino y el almaen el penfamiento/llegue aqui a pería fiel/como dixo diego de fant Pedro. Do quedobefan do las manos de vuefrasmer cedes.

Aquife acaba la carcel deamor.

ULo ăfefigue noes dela obra/mas pufofe aqui porquenovuieffetanto papel blanco/yes buenaletus ra/y verdadera.

h. H6v
h. $\mathrm{H} 7 \mathrm{r}$
h. $\mathrm{H} 7 \mathrm{r}$ 
La Qüestión de amor no incluye una rúbrica inicial propiamente dicha, pero sí que presenta el titulillo QVESTION en la h. A3v, que en la h. A4r no se completa, como en el resto del impreso, con el encabezado DE AMOR, sino que este se sustituye por COMIENZA LA OBRA. Desaparece, por tanto, la solidaridad entre los dos primeros titulillos en la unidad de lectura u opening. En la h. A2r se incluye PROLOGO como encabezado; en la A2v, EL PROLOGO; y en la A3r EL ARGUMENTO, respectivamente. La primera vez en que QVESTION y DE AMOR se pueden leer como título completo es en las hojas A4v-A5r. El hecho de que se trunque en la unidad de lectura anterior, podría evidenciar una cierta improvisación al introducir la indicación de inicio de obra. Si no se hubiesen previsto los titulillos QVESTION y DE AMOR para el opening A3v-A4r y se hubiese pensado desde un principio en introducir COMIENZA LA OBRA en A4r, sería más lógico haber puesto EL ARGUMENTO en A3v, repitiendo el titulillo de A3r, de la misma manera que se hace PROLOGO (A2r) y EL PROLOGO (A2v), con lo que se evitaría el truncamiento del título de la obra. Para la Qüestión de amor no se había previsto, por tanto, un conector tipográfico de inicio, pero -o por lo cual- se incorpora posteriormente un titulillo de encabezado, improvisándolo, algo que no ocurrirá ya en el resto de obras.

Todas las rúbricas iniciales de las siguientes secciones de esta edición presentan unos rasgos comunes, como es el caso del uso de tres tipografías de diferente tamaño, en degradación, y una disposición en pie de copa. Ahora bien, la rúbrica de la Cárcel de amor de Diego de San Pedro difiere de la que precede a la continuación de Nicolás Núñez y de la que encabeza la sección de los poemas de remate, dos secciones que, por su parte, comparten los rasgos de decoración tipográfica: una hedera u hoja acorazonada, tras la cual se incorpora SIGVE con una tipografía de tres líneas de escritura ${ }^{66}$, mientras que, a continuación, se usan las mismas mayúsculas de los titulillos y, finalmente, cuatro líneas con los tipos del cuerpo de la edición, que son las que van reduciendo su caja en triángulo invertido. Sin embargo, para la rúbrica de la Cárcel de amor de Diego de San Pedro se recurre al calderón y no a la hoja acorazonada, se usa una tipografía solo ligeramente superior a la de los titulillos, con la que se compone la segunda línea, y no son cuatro, sino siete las líneas de escritura con el tipo menor, aunque las dos primeras mantienen la justificación de las anteriores y solo se van reduciendo las cinco últimas. Todos ellos son, en cualquier caso, conectores tipográficos que estructuran la edición y permiten fácilmente el reconocimiento de sus metatextos y, por

${ }^{66}$ Con la matriz de la V mal justificada en el caso de la rúbrica de la Cárcel de amor de Núñez. 
tanto, la delimitación de las obras y de las secciones del producto editorial en cuestión.

El inicio de los textos de las tres obras sentimentales, como hemos visto, está claramente indicado por una capitular grabada y muy ornada, compartida en la anónima Qüestión de amor y en la Cárcel de amor de San Pedro, y de un juego diferente al que inaugura la obra de Núñez. Frente a esta relativa sistematicidad, las peculiaridades de la última sección, con tres romances y el cabo de un villancico, es evidente al recurrir a una inicial lombarda para inaugurar el primero de los poemas. Sin duda, es el recurso de organización textual más destacado en cuanto a la decoración tipográfica de los cuatro poemas y lo es porque inaugura la sección; es por eso que no se vuelve a repetir en los otros tres poemas y que no requiere una rúbrica individual, a diferencia de ellos.

Para la rúbrica del segundo y del cuarto poema, se usa la tipografía propia de los titulillos de encabezado, mientras que para el tercero se recurre a la misma decoración tipográfica de la rúbrica de la Cárcel de amor de Diego de San Pedro: el uso del calderón, los mismos tres modelos tipográficos y con idéntica distribución, y el pie de copa para la letra de menor tamaño.

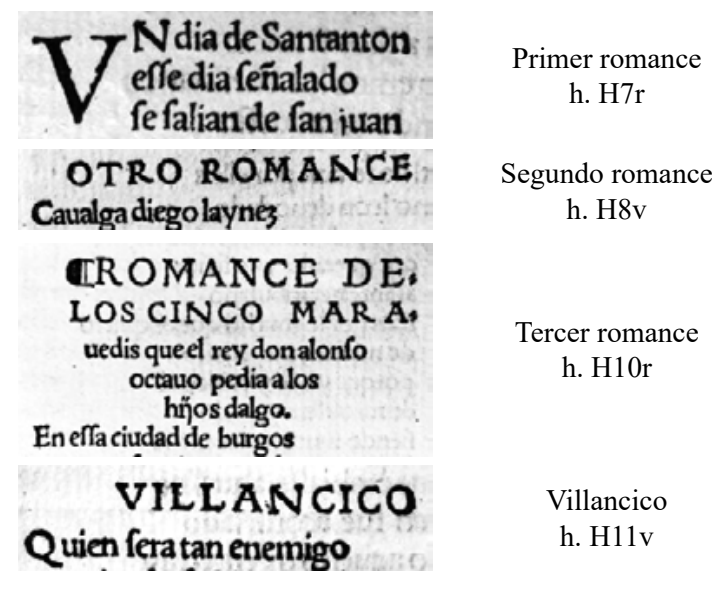

El primero de los poemas y el villancico indican Fin para cerrar la obra, pero no es así con el segundo y tercero de los romances, ni tampoco contamos con ninguna rúbrica de fin de obra común para la sección de poemas de remate, a diferencia de lo que ocurre con los textos sentimentales. La Qüestión de amor se concluye con un simple Deo gracias, que podría provenir de su antígrafo, precedido de la firma de la carta final de la obra distribuida en pie de copa, como organizador tipográfico. Este mismo recurso se utiliza para 
cerrar el texto de la Cárcel de amor de Nicolás Núñez, las últimas seis líneas del cual se van reduciendo. Tanto la obra de San Pedro como la de Núñez se rematan con una rúbrica de fin casi idéntica, con calderón en el primer caso y con alternancia de género para el término cárcel, en masculino y, después, en femenino: «Aqui se acaba el/la carcel de amor». Ambos textos son, por tanto, la Cárcel de amor y, al mismo tiempo, ambos forman una unidad indisoluble desde época incunable. La segunda de estas rúbricas delimita el texto de Núñez, pero también el conjunto de la obra y de ahí la homonimia. Tras esta rúbrica, Martín Nucio, en una anotación que decora con pie de copa, como texto de cierre que es, deja constancia de lo ajeno de los materiales añadidos a continuación y de la razón por la que lo hace:

\section{CLo que se sigue no es de la obra/ mas puso se aqui porqueno vuiesse tanto papel blanco/ y es buena letu= $\mathrm{ra} / \mathrm{y}$ verdadera.}

En la h. H6v se acaba, por tanto, el texto de las obras previstas para este impreso de San Pedro y Núñez, destinado a formar una edición conjunta con el de la Qüestión de amor, de manera que quedan en blanco seis hojas, de las que Nucio destina cinco a cuatro poemas de remate, deja en blanco el recto de la última y en su vuelto incluye su escudete de impresor, como había hecho con el impreso anterior.

\section{En conclusión}

Aunque el modelo de edición conjunta de dos impresos se conoce desde época incunable, Martín Nucio es el primero en aplicarlo a la rica tradición impresa de la Cárcel de amor, reinventando el producto literario en un formato bibliográfico que arraiga y que se imita en ediciones posteriores, no solo en aquellas que produce el taller de los Nucio en 1556, 1576 y 1598, sino especialmente en la parisina de 1548 de los Caldera y en la salmantina de Pedro Lasso Vaca de 1580. La de Medina del Campo de Pedro de Castro de 1547 y la zaragozana de Esteban de Nájera de 1551 deben concebirse también, a mi parecer, en su órbita de influencia, en ambos casos con una dependencia más sutil, a la manera de lo ocurrido con el Cancionero de romances y la primera parte de la Silva.

Los rasgos materiales de la editio princeps de 1546 responden a su idiosincrasia como reunión de impresos dependientes y/o complementarios, pero 
algunos de ellos, como la unificación de las signaturas de cuadernos, se resuelven en las dos ediciones siguientes de los Nucio, una vez testado su éxito comercial como producto unitario. Es, precisamente, este modelo editorial y comercial el que relega la Cárcel de amor a un segundo lugar, no como agravio, sino por su posible venta como impreso independiente, desprovisto de referencias a la Qüestión de amor. Algunas de las peculiaridades de la edición son, sin embargo y muy probablemente, deudoras de la materialidad de su antígrafo, mientras que otras, como la irrupción del novedoso dozavo en la tradición editorial de la obra de San Pedro, caracteriza, en realidad, la imprenta nuciana.

Los cuatro grabados del escudete de Martín Nucio permiten datar los impresos en las primeras semanas de 1546, mientras que la presencia de tres capitulares y su diferente morfología se explican por la idiosincrasia de la edición, tanto por la estructura interna tripartita del proyecto original, como por tratarse de un producto de faltriquera que mantuviera en el mercado, sin lujos que lo encarecieran, unas obras literarias de larga tradición editorial. No solo las portadas, los escudos o las capitulares funcionan como organizadores textuales, sino que otros rasgos tipográficos de la decoración de estos impresos permiten delimitar su estructura, lo que, unido a su relativa sistematicidad, también aporta datos sobre el proyecto editorial y su modificación en el taller de imprenta.

Así ocurre con la adición de los poemas de remate: su rúbrica inicial comparte decoración con la que encabeza la Cárcel de amor de Nicolás Núñez, cuyo texto acaba a mitad del último cuaderno y, al componerse para un plegado en dozavo, deja en blanco un total de seis hojas. Martín Nucio, «porque no uviesse tanto papel blanco», recurre a materiales de uno de los pliegos poéticos que ya tenía entonces en su poder y que acabarían nutriendo su Cancionero de romances, de cuyo contenido se seleccionan los materiales a los que daban cabida las hojas en blanco. Esta última sección no se puede identificar, por tanto, con un pliego completo, como da a entender Rodríguez Moñino ${ }^{67}$, sino como unos materiales seleccionados de un pliego poético hoy perdido, pero, sin duda, burgalés e impreso por Juan de Junta, como explicaré en otro trabajo.

${ }^{67}$ Antonio Rodríguez Moñino, Nuevo Diccionario bibliográfico de pliegos sueltos poéticos (siglo $X V I$ ), ed. corregida y actualizada por Arthur L. F. Askins y Víctor Infantes, Madrid, Castalia, 1997, pp. $576-577$, n. $^{\circ} 694$ [+693]. 
MODELO EDITORIAL Y MORFOSINTAXIS MATERIAL DE UNA EDICIÓN DE MaRTíN NuCIO: LA QÜESTIÓN DE AMOR Y LA CÁRCEL DE AMOR (1546)

Resumen: El taller de Martín Nucio se caracteriza por innovar en cuanto a los formatos editoriales de obras de larga tradición literaria y editorial. A partir del conocimiento de cada uno de ellos, podremos entender mejor el funcionamiento de este taller de imprenta; y es desde la solidez de este conocimiento que podremos interpretar la historia editorial de una obra concreta. Uno de estos exitosos e innovadores productos bibliográficos es el objeto de este trabajo: la edición conjunta de dos impresos de carácter sentimental. El primero de ellos recoge la anónima Qüestión de amor; el segundo, la Cárcel de amor de Diego de San Pedro y su continuación, obra de Nicolás Núñez, que se completa, circunstancialmente, por cuatro poemas de remate provenientes de un pliego poético hoy perdido. Este trabajo estudia este peculiar modelo editorial y los rasgos de decoración tipográfica, desde una perspectiva morfológica y macrosintáctica.

Palabras Clave: Martín Nucio. Flandes. Imprenta. Cárcel de amor. Qüestión de amor. Diego de San Pedro.

EDITORIAL MODEL AND MATERIAL MORPHOSINTAXIS OF AN EDITION OF MARTÍN NUCIO: THE QÜESTIÓN DE AMOR AND THE CÁRCEL DE AMOR (1546)

ABSTRACT: Martín Nucio's printing office is characterized by innovating in the editorial formats of works of long literary and editorial tradition. From the knowledge of each of them, we can better understand the operation of this printing shop; and it is from the strength of this knowledge that we can interpret the editorial history of a specific work. One of these successful and innovative bibliographic products is the object of this work: the joint edition of two forms of sentimental pieces. The first one includes the anonymous Qüestión de amor; the second, Diego de San Pedro's Cárcel de amor and its continuation, by Nicolás Núñez, which is completed, circumstantially, by four poems from a poetic sheet today lost. This work studies this peculiar editorial model and typographic decoration features, from a morphological and macrosyntactic perspective.

KeYwords: Martinus Nutius. Flanders. Printing. Cárcel de amor. Qüestión de amor. Diego de San Pedro. 